\title{
Differential effects of conjugated linoleic acid isomers in an in vitro model of HIV lipodystrophy
}

\author{
C. R. Loonam, S. D. O'Dell and A. Mullen \\ Diabetes and Nutritional Sciences Division, King's College London, SE19NH.
}

Ritonavir is an antiretroviral drug used in the management of HIV and is associated with abnormalities of body fat distribution particularly peripheral lipoatrophyl. This is thought to occur as a result of adipocyte dysfunction caused by down-regulation of the transcription factor PPAR $-\gamma^{2}$. We have previously shown ritonavir-induced decreases in triglyceride accumulation, and PPAR- $\gamma$ and adiponectin gene expression in 3T3-L1 adipocytes ${ }^{3}$. In this study, we investigated the effect of two conjugated linoleic acid (CLA) isomers, as putative PPAR- $\gamma$ ligands, on adipocyte function and PPAR- $\gamma$ and target gene expression.

Murine 3T3-L1 adipocytes were treated with physiological concentrations $(20 \mu \mathrm{M})$ of ritonavir, as well as $100 \mu \mathrm{M}$ of two CLA isomers, c9,t11 and t10,c12, for 5 days. Triglyceride accumulation was investigated using Oil Red O stain, gene expression using TaqMan $^{\circledR}$ gene expression assays, protein secretion using a sandwich ELISA and nuclear PPAR- $\gamma$ binding using a DNA-binding ELISA. Data from four parallel cell culture experiments were analysed using ANOVA in SPSS version 20. Statistical significance was taken at $P<0.05$.

Both c9,t11 and t10,c12 significantly increased triglyceride accumulation compared with control $(\mathrm{P}<0 \cdot 001)$. No effect was observed for either isomer on PPAR- $\gamma$ gene expression. $\mathrm{c} 9, \mathrm{t} 11$ increased PPAR- $\gamma$ nuclear binding $(\mathrm{P}=0 \cdot 038)$, while t10,c12 had no significant effect. t10,c12 decreased PPAR- $\gamma$ target gene adiponectin expression $(\mathrm{P}=0.038)$ and adiponectin protein secretion $(\mathrm{P}=0.003)$; no effect was observed for $\mathrm{c} 9, \mathrm{t} 11$. t10,c12 decreased lipid droplet protein perilipin expression $(\mathrm{P}=0.004)$, while c9,t11 had no effect.

Overall, the results indicate differential effects of the two CLA isomers. Both show potential in improving lipid storage in adipocytes treated with ritonavir. c9,t11 beneficially increased PPAR- $\gamma$ nuclear binding, while t10,c12 detrimentally altered the expression of genes involved in lipid storage. In conclusion, c9,t11, but not t10,c12, may have potential therapeutic effects in attenuating lipoatrophy associated with antiretroviral therapy.

This work was supported by a grant from the Nutricia Research Foundation.

1. Mencarelli A, Francisci D, Renga B et al. (2012) Antivir Ther. 17, 669-78.

2. Caron M, Vigouroux C, Bastard JP et al. (2009) PPAR Res. 2009, 507141.

3. Loonam C, O'Dell S, Mullen A (2012) Proc Nut Soc. 71, OCE2, E120. 